Proceeding Paper

\title{
Hybrid Adaptation Scientific Investigations and Mentoring System in Geopolygons Conditions ${ }^{+}$
}

\author{
Kseniia Nepeina
}

Citation: Nepeina, K. Hybrid Adaptation Scientific Investigations and Mentoring System in Geopolygons Conditions. Environ. Sci. Proc. 2021, 5, 18. https://doi.org/ 10.3390/IECG2020-08739

Academic Editor: Jesus Martinez Frias

Published: 1 December 2020

Publisher's Note: MDPI stays neutral with regard to jurisdictional claims in published maps and institutional affiliations.

Copyright: $(\subset) 2020$ by the authors. Licensee MDPI, Basel, Switzerland. This article is an open access article distributed under the terms and conditions of the Creative Commons Attribution (CC BY) license (http://creativecommons.org/licenses/by/4.0/).

\author{
Research Station of the Russian Academy of Sciences in Bishkek, Bishkek 720049, Kyrgyzstan; \\ nepeina.k@mail.ru; Tel.: +996-312-61-31-40 \\ + Presented at the 3rd International Electronic Conference on Geosciences, 7-13 December 2020; \\ Available online: https://iecg2020.sciforum.net/.
}

\begin{abstract}
In this work, the view of a series of practical research-and-educational activities and mentorship within the institute Research Station of the Russian Academy of Sciences in Bishkek (RS RAS) are presented. STEM learning on-site, specifically related to the Earth sciences, is important. RS RAS in Bishkek is studying geodynamics, stressed and deformed state and deep structure of Tien Shan, seismotectonic, and geoenvironmental and engineering-geological aspects. All field activities have been continued and have been made by special groups of maximum 3 persons. At the RS RAS, a mentorship program within the organization for mentees is introduced. However, COVID-19 quarantine forced us to make mostly online seminars for organization staff and provide online educational training for the students of American University of Central Asia (AUCA) and Kyrgyz Russian Slavic University (KRSU). Under the support of the Rossotrudnichestvo, the agreement on scientific and technical cooperation between the Kyrgyz National University named after Jusup Balasagyn and the RS RAS was signed on 30 September 2020. I admit that the new remote technologies should be included in future development because the accessible geophysical equipment degrades rather quickly and especially because of daily use and temperature changes.
\end{abstract}

Keywords: geopolygon; field training; mentorship; on-site education; online training

\section{Introduction}

In this work, I show the mentoring system at the Research Station of the Russian Academy of Sciences in Bishkek (RS RAS) during 2020 and how COVID-19 affects the systematic professional field training. Employees' competences are central and were formed mostly in universities and practical experience. The mentoring system was introduced in 2019 for a stimulating learning environment and improve ability to teach, to manage the time schedule, stay courageous between colleagues and transfer knowledge, gained through practical experience. At the Research Station RAS in Bishkek, we lead a mentorship program within the organization for mentees. During the COVID-19 pandemic more digital competences were faced, especially from April 2020, when the quarantine was introduced. Some part-time senior scientists struggled suspense with online education and convening online education trainings for university students.

Usually in summer time, our staff provide some internship spots for students from different areas of study (IT, mining engineer, civil Engineers, etc.) to train some educated skills. RS RAS (http://www.gdirc.ru/en, accessed on 18 November 2020) [1] is an academic institution and is a part of Bishkek Geodynamic Proving Ground of the International Research Center (IRC BGPG) with the Multiple-Access Geosciences System (MAGS) (http://ckp-rf.ru/ckp/500801/, accessed on 18 November 2020) [2] studying geodynamics, stressed and deformed state and deep structure of Tien Shan, seismotectonic, and geoenvironmental and engineering-geological aspects. For the internships and trainings, RS 
RAS uses the geopolygons-test sites, under the historical view of a series of practical research-and-educational activities. In this sense, STEM learning on-site, specifically related to the Earth sciences, is important [3]. However, COVID-19 quarantine forced us to make mostly online seminars for organization staff and provide online educational training for the students of the American University of Central Asia (AUCA) [4] and Kyrgyz-Russian Slavic University (KRSU) [5].

Under hybrid adaptation in geopolygons conditions, I mean the joint approach to work (provide scientific investigations and mentorship) either online in web space or offline in natural outcrops. All data storage from on-site stationary monitoring points of BGPG has been still offline. All field activities have been continued and have been made by special groups of a maximum of 3 persons. I admit that the new remote technologies should be included in future development because the accessible geophysical equipment degrades rather quickly and especially because of daily use and temperature changes.

This adaptation follows the GEO major goals [6]:

1. Use Internet tools that are intuitive, that are relevant to "real" life

2. Make this new technology accessible to an ever-wider community

3. Use the technology to promote project-based experimentation, field measurements, and data interpretation

4. Create and support an environment wherein mentee and mentors can communicate without barriers in a different form (as video, filming, creation, programming, etc.)

\section{Materials and Methods}

Mentorship within the organization is linked to the professional and relational competences development during in-service maintenance [7-12]. The shift to online-based activities is a necessary measure in geosciences teaching and Earth sciences research under physical distancing conditions and requirements. There are 6 research engineers and 20 research scientists, and 12 among them are less than 40 years old within RS RAS. Some of the employees are involved in the educational process with the basic universities in Kyrgyzstan, situated in Bishkek city: Kyrgyz-Russian Slavic University (KRSU) (https://www.krsu. edu.kg/, accessed on 18 November 2020) [5], American University of Central Asia (AUCA) (https://www.auca.kg/en/main/, accessed on 18 November 2020) [4], and Kyrgyz National University named after Jusup Balasagyn (KNU) (https://www.knu.kg/en/, accessed on 18 November 2020) [13].

The main education cooperation faculties at KRSU are:

- Faculty of Architecture, Design and Construction-Department of Water Resources and Engineering Disciplines

- Faculty of Natural and Technical Disciplines-Department of Physical Processes of Mining and Oil and Gas Production and Department of Information and Computing Technologies

At the faculties, the following disciplines are in the program:

- Geophysics

- Mining geophysics

- Basics of mining and oil and gas business

- Construction geotechnology

- Measurements in a physical experiment

- Hydrogeology

- Programming languages and methods, object-oriented programming, system software, computer graphics.

The traditional hydrogeological field training for KRSU students from the Faculty of Architecture, Design and Construction-Department of Water Resources and Engineering Disciplines consists of:

- Geomorphological complexes (types of relief) description 
- Matching geomorphological features with the on topographic maps of different scales

- The connection of geomorphological complexes with hydrogeological structures in the river canyons in BGRG

- Processes of physical weathering;

- Exogenous processes (erosion, landslides, suffusion, and the surface activity of water springs

- Physical properties of minerals, their structural structures, and forms of occurrence in nature

- An individual report preparation.

The following courses for AUCA students of natural and technical specialties and with economic applications for students of business administration and economics are:

- $\quad$ Linear Algebra and Analytical Geometry

- Mathematical Analysis

The traditional internship for students of the Department of Applied Mathematics and Informatics of AUCA consists of tasks description, some explanations from tutors, task completion by tutees, and individual report preparation.

The relationship between RS RAS and KNU is based on the agreement on scientific and technical cooperation, signed 23 March 2018 [1]. The joint meetings, excursions for students, and exchange of presentations have been organized since then.

The geopolygon conditions are conducive, when there is quite uninhabited (thinly populated). That is why we could keep social distancing. There is also some geophysical equipment (e.g., gravimeter Scintrex CG-5) on-site within the RS RAS area in natural conditions. So, it is useful for the demonstration of the power of the available geophysical monitoring equipment. It was common during the conferences for young students and young researchers (Figure 1).

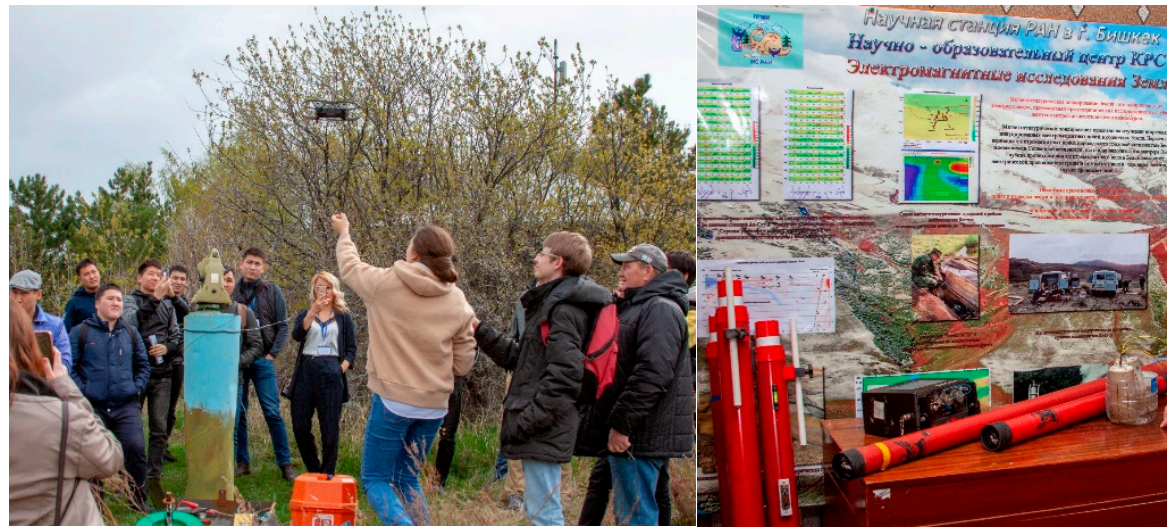

Figure 1. Field demonstration of the quadcopter shot by the Global Positioning System laboratory RS RAS and equipment exhibition for the magnetotelluric investigations. The activity was made during the conference for young scientists, PhD, and graduate students in 2018 (photo credit (C) RS RAS).

Under the quarantine, both the students and RS RAS staff faced temporary displacement difficulties. This is why all activities were moved to online webspace. This does not mean that we abandon all on-site activities, but this is an available alternative, at least in part (even if there are some core activities that should remain on-site). The data collection process for the students was simulated by themselves, looking for the rocks in the surroundings. During a lack of research and the measurements under lockdown, the day-today processes were targeted to the webinar preparations, discussions, and collaboration in the other aspects. This is another side of continuous learning for the improvement of practice and for the sake of adult mentees. I agree with [14] in the point that "Despite all 
of this new technology and its incorporation into today's field trips, there is still an intrinsic pedagogical need for physical field trips." Fieldwork is a defining aspect of the geosciences. It, therefore, needs to assume a central role in geoscience education.

According to [15], "the geoscience education arena one does find many a critical note on the required skill set of a geoscientist; to name a few:

- Complexity of Earth Systems and the skills that Geoscientists need;

- Math and complexity in education;

- Logic reasoning.

Mobile technologies became so necessary during the lockdown. Skype application is a useful tool to entertain chat and videoconferencing for a small group such a scientific laboratory in education and research aspect [16]. Video chat technology and webinars. The mentee had enough time to attend Web of Science, Scopus, Wiley, and Springer series of webinars. Therefore, the mentorship within RS RAS has a limited time: the duration of the webinar is no longer than $3 \mathrm{~h}$ per week.

The mentor's role of "being a guide" involved providing specific guidance on things that they have already experienced to the mentees. In addition, the field where the mentees are unfamiliar with and when individuals are tasked with a developing goal to train geological-and-mining or computational tests on the verified tested area. The research teams attempt advances in digital data to create new computer processing tools to produce transformative research. The schematic mentoring process is shown in Figure 2.

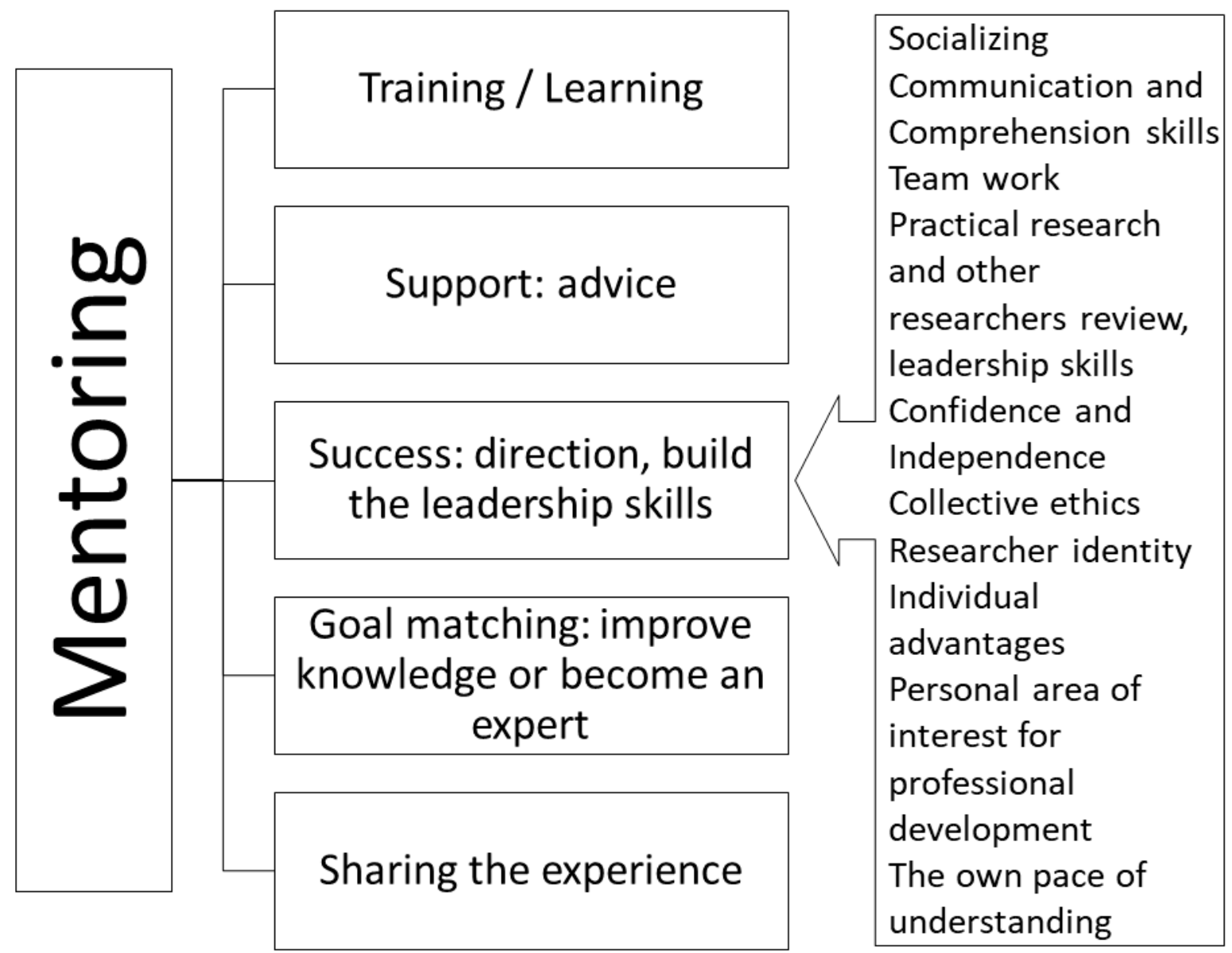

Figure 2. Scheme for the mentoring process and habit formation. 


\section{Results}

Internal webinar of the Laboratory of deep magnetotelluric investigations (LDMI) consolidated around 10 participants via Skype. Since January 2020, we produce 34 webinars about equipment for electromagnetic (EM) methods, EM theory, geological-and-geophysical interpretation, geoelectric anomalies and noise correction, features of digital processing, and direct modeling for the impedance calculation. Some webinars are likely workshops, where the mentor is showing the processing actions on the screen.

The webinars could be now documented-they are recorded, so the questions and specific difficulties that occurred can be used in the future training programs with the core participants, as well with the total research group. However, some troubles occurred due to a lack of computing power and memory, free Skype version, and unstable internet connection.

Under the support of the Federal Agency for the Commonwealth of Independent States Affairs, Compatriots Living Abroad, and International Humanitarian Cooperation (Rossotrudnichestvo), the agreement on scientific and technical cooperation between the Kyrgyz National University named after Jusup Balasagyn (KNU) and the Research Station RAS in Bishkek was signed on 30 September 2020. The accumulated knowledge now could be structured and easily lectured in KNU.

\section{Discussion}

Authors should discuss the results and how they can be interpreted in the perspective of previous studies and of the working hypotheses. Future research directions may also be highlighted. Remote operations could also allow a more flexible schedule, but not applicable for the old-fashion equipment and cannot be performed today exclusively by remote means. All data storage from on-site stationary monitoring points of Bishkek Geodynamic Proving Ground has been still offline. However, the seismological network KNET provides data through telemetric signals. The future online webinars could be enhanced by online analyses of terrains and outcrops and fieldwork operations controlled by remote operators such as operated vehicles for the acquisition of images, radiations, etc., for mineral exploration work or geotechnical studies.

\section{Conclusions}

The hybrid adaptation as the online and offline approach was launched successfully. The educational trainings were passed with new tools and, in different conditions under the creativity and enthusiasm of tutors, faced the modified way. The webinar preparation helps to identify leadership talents inter small groups. It could be power resources for future interactions. The mentorship within the institution becomes the most desirable for cost-time reasons.

Such kind of mentor activity is a way of helping to find a solution for new research grant proposals. Mentees benefit from a different way of learning-on-site and online. The focus of this proceeding is still on the contribution to geological teaching and research in Earth Sciences. "The relationship between mentor and mentee can provide strong academic and professional support and can potentially lead to interpersonal relationships" [17]. However, the stress rate of webinars preparation and studying in remote conditions pose some other difficulties: resolving technical difficulties beforehand (e.g., inadequate access to resources such as computers, webcams, reliable internet, and learning spaces free of distractions [18]), self-management and self-control, developing digital literacy, and netiquette. For some groups of workers, it is better to learn some technical features and more knowledgeable webinars outside the institution, e.g., EMinars (https://www.mtnet.info/webinars/webinars.html. accessed on 19 November 2020) [19], free access to SEG Honorary Lecture Program or other professional societies (SSA, AGU, PaleoPERCS, etc.), online courses Coursera or other projects. 
Institutional Review Board Statement: Not applicable.

Informed Consent Statement: Not applicable.

Data Availability Statement: Data sharing not applicable.

Acknowledgments: The research is partly funded by the state assignment of the Ministry of Science and Higher Education of the Russian Federation for the Research Station of the Russian Academy of Sciences (AAAA-A19-119020190063-2). I thank the ideological support of the international cooperation on scientific and technical cooperation between the Kyrgyz National University named after Jusup Balasagyn (KNU) and the Research Station RAS in Bishkek under the support of the Federal Agency for the Commonwealth of Independent States Affairs, Compatriots Living Abroad, and International Humanitarian Cooperation (Rossotrudnichestvo). I especially acknowledge my colleagues to share their experience and to be involved in mentorship, trainings, and webinars.

Conflicts of Interest: The author declares no conflicts of interest. The founding sponsors had no role in the design of the study; in the collection, analyses, or interpretation of data; in the writing of the manuscript; and in the decision to publish the results. This research did not receive any specific grant from funding agencies in the public, commercial, or not-for-profit sectors.

\section{Abbreviations}

RS RAS Research Station of the Russian Academy of Sciences in Bishkek

\section{References}

1. Research Station RAS. Available online: http://www.gdirc.ru/en/ (accessed on 18 November 2020).

2. Multiple-Access Geosciences System (MAGS). Available online: http://ckp-rf.ru/ckp/500801/ (accessed on 18 November 2020).

3. Nepeina, K.; Istomina, N.; Bykova, O. The Role of Field Training in STEM Education: Theoretical and Practical Limitations of Scalability. Eur. J. Investig. Health Psychol. Educ. 2020, 10, 511-529, doi:10.3390/ejihpe10010037.

4. Kyrgyz-Russian Slavic University. Available online: https://www.krsu.edu.kg/ (accessed on 18 November 2020).

5. American University of Central Asia. Available online: https://www.auca.kg/en/main/ (accessed on 18 November 2020).

6. Pedersen, P.J.; Woolum, S.; Gagne, B.; Coleman, M. Beyond the Norm: Extraordinary Relationships in Youth Mentoring. Child. Youth Serv. Rev. 2009, 31, 1307-1313, doi:10.1016/j.childyouth.2009.06.001.

7. Kim, K.H.; Zabelina, D.L. Mentors. In Encyclopedia of Creativity; Elsevier: Amsterdam, The Netherlands, 2011, pp. 102-106, doi:10.1016/B978-0-12-375038-9.00145-X.

8. Stelter, R.L.; Kupersmidt, J.B.; Stump, K.N. Establishing Effective STEM Mentoring Relationships through Mentor Training. Ann. N. Y. Acad. Sci. 2020, 1483, 224-243, doi:10.1111/nyas.14470.

9. Ma, Y.; Mukherjee, S.; Uzzi, B. Mentorship and Protégé Success in STEM Fields. Proc. Natl. Acad. Sci. USA 2020, 117, 1407714083, doi:10.1073/pnas.1915516117.

10. Polidoro, B.; Clement, C. Beyond Citizen Science: Multigenerational Education and Mentoring in Environmental Monitoring-A Case Study. Integr. Environ. Assess. Manag. 2018, 14, 521-522, doi:10.1002/ieam.4043.

11. Mullen, C.A.; Klimaitis, C.C. Defining Mentoring: A Literature Review of Issues, Types, and Applications. Ann. N. Y. Acad. Sci. 2019, 1483, 19-35, doi:10.1111/nyas.14176.

12. Hund, A.K.; Churchill, A.C.; Faist, A.M.; Havrilla, C.A.; Love Stowell, S.M.; McCreery, H.F.; Ng, J.; Pinzone, C.A.; Scordato, E.S.C. Transforming Mentorship in STEM by Training Scientists to Be Better Leaders. Ecol. Evolut. 2018, 8, 9962-9974, doi:10.1002/ece3.4527.

13. Kyrgyz National University Named after Jusup Balasagyn. Available online: https://www.knu.kg/en/ (accessed on 18 November 2020).

14. Cliffe, A.D. A Review of the Benefits and Drawbacks to Virtual Field Guides in Today's Geoscience Higher Education Environment. Int. J. Educ. Technol. High. Educ. 2017, 14, 28, doi:10.1186/s41239-017-0066-x.

15. Mikeš, D. Geoscience education is outdated. S. Afr. J. Geol. 2015, 118, 299-301, doi:10.2113/gssajg.118.3.299.

16. Janghorban, R.; Roudsari, R.L.; Taghipour, A. Skype interviewing: The new generation of online synchronous interview in qualitative research. Int. J. Qual. Stud. Health Well-Being 2014, 9, 24152, doi:10.3402/qhw.v9.24152.

17. Farah, R.S.; Goldfarb, N.; Tomczik, J.; Karels, S.; Hordinsky, M.K. Making the most of your mentorship: Viewpoints from a mentor and mentee. Int. J. Women's Dermatol. 2020, 6, 63-67, doi:10.1016/j.ijwd.2019.12.002.

18. Neuwirth, L.S.; Jović, S.; Mukherji, B.R. Reimagining higher education during and post-COVID-19: Challenges and opportunities. J. Adult Contin. Educ. 2020, doi:10.1177/1477971420947738.

19. EMinars. Available online: https://www.mtnet.info/webinars/webinars.html (accessed on 19 November 2020). 